patient got the largest subconjunctival haematoma I have ever seen : at the end of the operation it stood up round the lower and inner part of the cornea, looking very much like a kidney with the hilum at the limbus. Before bandaging the eye I tapped this haematoma with a cut from a pair of scissors. Recovery was uneventful and the case left hospital at the end of the month.

'Tested in out-patients' department on September 1, 1926, the visual result was: R.E. +0.75 cyl. axis horizontal $=6 / 9$. There was a large myopic crescent, the macula was healthy as was the vitreous, and the spindle was very obvious; it could be seen with focal illumination by the naked eye. I could not discover any trace of a spindle in the blind eye.

Seen by the aid of the slit-lamp the change in the cornea appears to be more diffuse than one would be led to expect by simple examination with the loupe; to the latter the appearance was really that of a spindle more or less in the centre of the cornea.

The picture by Theodore Hamblin, Ltd., with the aid of the slit-lamp, shows the condition excellently. I am indebted to $\mathrm{Mr}$. Duke-Eider for the trouble he took in attending with the patient and showing the draughtsman exactly what was wanted.

\title{
TREATMENT OF TRACHOMA BY ACETIC ACID
}

BY

\author{
J. A. LeA \\ NATAL
}

Having seen lately in the British Journal of Ophthalmology several papers, more especially abstracts from foreign sources on the treatment of trachoma, and having noticed how varied the treatment was, and in some instances severe, I am encouraged to give my experience of a plan of treatment which I have found successful during the time that I have practised as an ophthalmic surgeon in South Africa.

When first I came to South Africa several years ago I found trachoma very prevalent, more especially in the, dry, dusty upcountry districts; and had many severe and neglected cases to attend. I used the usual remedies with only moderate success. I then commenced this plan of treatment which I followed with success until I retired from practice a few years ago.

My method of procedure is as follows: I wash the eye and eyelids with a saturated solution of boracic acid. I then drop in a 0.5 per cent. solution of cocaine (I use Darier's solution which contains also adrenaline). I then take an instrument made for 


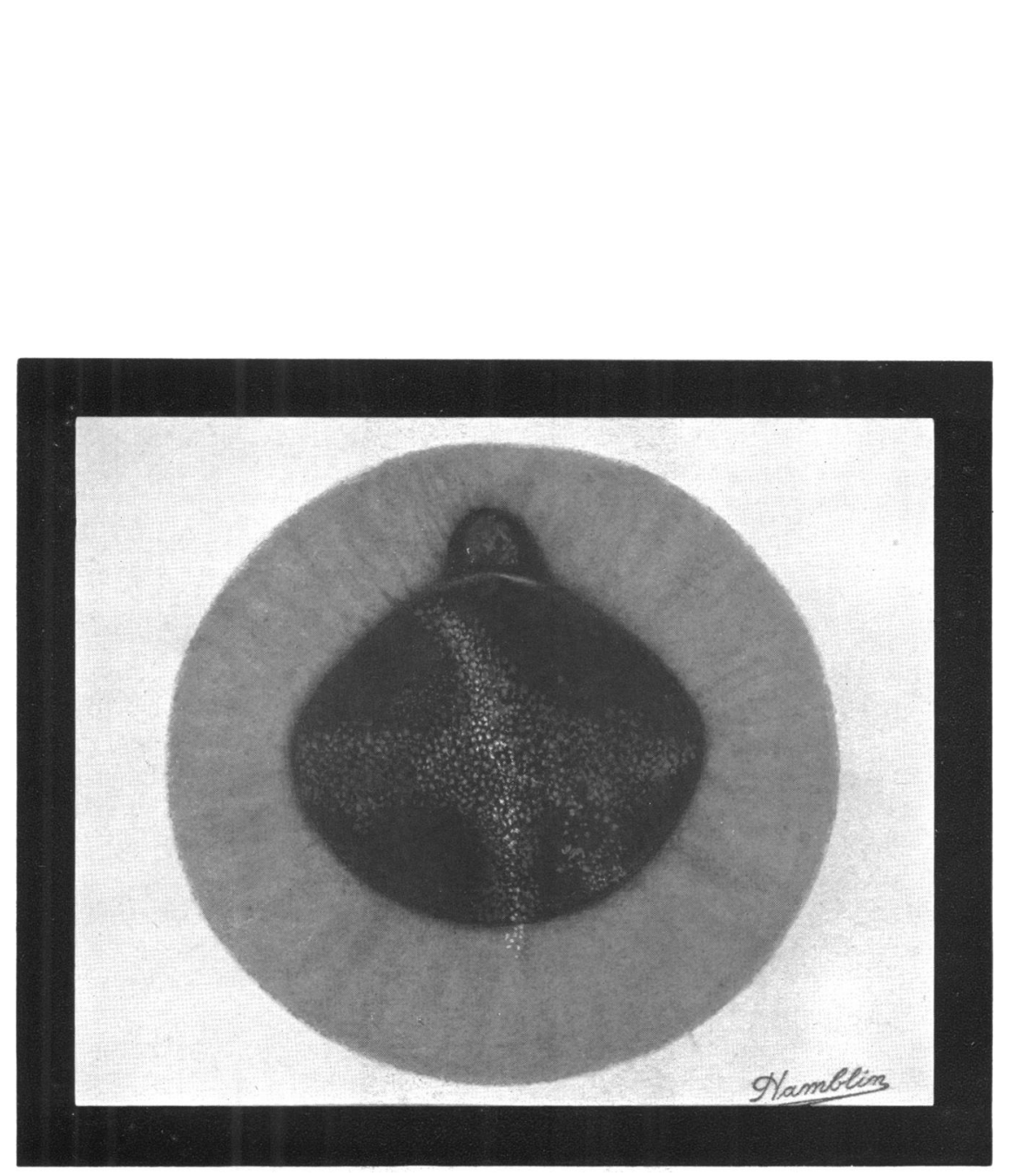

KRUKENBERG'S SPINDLE. 
me by Messrs. Weiss (an ordinary tattooing needle will do), dip it into a mixture of equal parts of acetic acid and water taking care to fill the groove, and having everted the eyelid, prick every true granulation and also very thoroughly any wavy rolls, or fringes of conjunctiva; wash again with a solution of boracic acid; and apply a cold compress to the eyelids for an hour or so.

This can be repeated two or even three times a week, and when the true granulations have disappeared I apply sulphate of copper to the hypertrophied papillae, alternating this with a 2 per cent. solution of nitrate of silver; more especially if the sulphate of copper causes too much irritation.

I have been astonished at the rapidity with which the true granulations, and wavy appearance of the conjunctiva disappeared after pricking with the acetic acid.

It is easy to do, as the true granulations are soft, the needle sinks in by its own weight, and consequently the operation is practically painless if carefully done.

It is useless as an application to the false granulations for which sulphate of copper seems to be a specific. I like to use a finepointed stick of sulphate of copper, and apply carefully to the granulations washing off any excess with a solution of boracic acid.

I have noticed in reading papers on the subject of trachoma that there is not only a want of unanimity in the methods of treatment, but there is also some want of agreement as to what constitutes a case of trachoma. I will therefore describe the kind of case seen in South Africa.

On everting the eyelids a velvety red surface interspersed with grey translucent dots is seen: these dots vary in size from that of a pin's head to that of a hemp seed; and in some cases in the fornices there are rolls of wavy-looking tissue; there is frequently some amount of pannus, and sometimes a facetted ulcer, or ulcers on the cornea. The amount of discomfort is usually less than one would expect from the appearance of the eye; and the ulcers have little tendency to break down or slough. These true granulations are soft, as are also the wavy masses, differing from the hypertrophied papillae which are firm, and the granulations of spring catarrh which are very hard. One often sees scar tissue on the conjunctival surface of the eyelid in old cases with bluish congested patches, and white lines.

I should like to relate a case which shows how long a case of trachoma may last, and that the lymphoid bodies may be concealed under the thickened conjunctiva. A Polish Jew, aged about 30 years, had suffered from his eyes from the time of his arrival in this country when aged about 12 years. He had had frequent attacks of inflammation of the eves relieved by treatment 
but never entirely cured. When I first saw him : on everting his upper eyelids I found the conjunctiva bluish and congested in patches with white lines of cicatrices, and no granulations. In the fornices were rolls of wavy semi-translucent looking conjunctiva; in the right eye there was a small facetted ulcer of the cornea with a clear surface, and some amount of pannus. I applied the acetic acid treatment to the wavy-looking conjunctiva, and followed it with applications of solution of nitrate of silver, 2 per cent., once every week. After 'several applications he appeared to be cured and I lost sight of him for a few months. He appeared again one day with acute inflammation of the right eye : on everting the eyelid I found a linear swelling extending along almost the whole length of the eyelid. Expecting to find. pus I incised the swelling, and uncovered four lymphoid bodies about the size of hemp seeds, which I removed.

I saw this man several times afterwards at long intervals, and found that his eyes gave him no more trouble except a little irritation on windy dusty days which might be expected from the dry cicatricial condition of his conjunctiva.

\section{BARRAQUER'S OPERATION}

BY

J. Russell Smith, M.R.C.S. LONDON

"I do not believe in violence-especially if it is not likely to be successful."

I AM indebted for this quotation to my father, Lt.-Col. H. Smith, C.I.E., I.M.S.(ret.), whose experience of some 50,000 cataract operations performed during his time as Civil Surgeon of Jallandar and Amritsar, Central Punjab, has been of the greatest assistance. to me in writing this article. The quotation is taken from the first edition of the "Collected Public Addresses of Gandhi," whose policy was to "spiritualize" Indian politics in order to bring them into harmony with the Holy Writ of Hinduism.

Professor Barraquer's article in Dr. W. A. Fisher's book on "Senile Cataract," in the edition published in 1923, by the Chicago Eye, Ear, Nose, and Throat College (obtainable from Messrs. $\mathrm{H}$. K. Lewis \& Co.), is a mine of information which well repays careful study. He seems to have evolved a method of dislocating and extracting the cataractous lens in its capsule, which, if the claims he makes for it are correct, constitutes a revolution of the very greatest importance. For to quote from page 38 : "Facoerisis 